\title{
Predicting Static Modulus of Elasticity of Laterite - Quarry Dust Blocks Using Osadebe's Regression Model
}

\author{
F. O. Okafor ${ }^{1}$ and *E. A. Egbe ${ }^{2}$ \\ ${ }^{1}$ Department of Civil Engineering, University of Nigeria, Nsukka \\ ${ }^{2}$ Operations Department, Cross River State Community \& Social Dev. Agency, Calabar Nigeria \\ *egbesonandy@yahoo.com
}

\begin{abstract}
The use of alternative materials other than river sand in the production of sandcrete blocks is gaining impetus in most major Nigerian cities. Manufacturers of these blocks are, however, faced with the problem of mix proportion required for the production of the desired property. Static modulus of elasticity of block is one key property required in the design of structures, which is usually neglected. In this work, a mathematical model is formulated using Osadebe's regression theory for predicting the static modulus of elasticity of laterite-quarry dust block. The model is tested for lack of fit using software and found adequate.
\end{abstract}

Keywords: Static modulus of elasticity, laterite, quarry dust, Osadebe regression model, mix proportion, Fisher Test.

\section{Introduction}

Walls or masonry units are the vertical members of a building or structure which enclose the space within it and which may also divide that space. Sandcrete blocks are still the most popularly and commonly used material for the construction of walls unit in all developing countries including Nigeria. They are prismatic precast units made from a combination or mix of well defined proportion of sand and cement. Sandcrete blocks according to [1], are blocks made or moulded with sand, water and cement, which serve as a binder in the matrix. As a result of the high cost and negative environmental impact caused by sand mining, one of the major constituents used in the production of blocks, alternative materials are being sought for and utilized in block production. Such alternative materials currently being used to partially or wholly replaced river sand includes: quarry dust, laterite, recycled aggregate, etc. The use of these alternative materials in blocks production and concrete works have been reported by several researchers. For instance, [2] carried out a study on the strength and durability of concrete utilizing quarry dust as full replacement for natural sand. They found a $10 \%$ improvement in the properties investigated over the conventional concrete made with natural sand. Also,[3] in their work on effects of granite fines on some engineering properties of sandcrete blocks recommended 15\% optimum replacement of sand with quarry dust in the production of sandcrete blocks. Also, the effect of partial replacement of sand with lateritic soil in sandcrete blocks was investigated by [4]. The study reveals that sand can be replaced up to $20 \%$ with laterite in sandcrete blocks. While most of the studies focus on some strength properties like compressive strength, properties like static modulus of elasticity $\left(E_{\mathrm{c}}\right)$ for blocks is scarcely documented. Knowledge of the value of static modulus of material is needed in structural design to avoid unrealistic assumptions.

There exist also the challenge of getting the appropriate mix proportion to attain a particular desired property as several methods of mix proportions have limitations and are usually not cost effective. Thus, researchers have worked on developing models for predicting properties of sand quarry dust and sand laterite block. A model for static modulus of elasticity for sand- quarry dust blocks was developed by [5]. Similarly, [6] developed a model for predicting the compressive strength and water absorption of sand - quarry dust blocks. Others works in this direction include those by [7] and [8]. This paper presents a model for predicting the static modulus of elasticity for laterite - quarry dust blocks. The model will help come up with the appropriate mix for laterite - quarry dusts blocks as well as help reduce the cost and effort expended in conducting trial mix.

The materials used for this work are:

\section{Materials And Method}

Cement

Unicem brand of Ordinary Portland cement, grade 32.5 obtained from a major dealer in Calabar conforming to BS 12 was used for all the tests.

Water

Potable pipe born water supplied by the Cross River State Water Board (CRSWB) Limited was used for both specimen preparations and curing. 


\section{Laterite}

Laterite was obtained from a borrow pit site at Akim - Akim in Odukpani Local Government Area of Cross River State. The specific gravity for the laterite is 2.56 .

\section{Quarry dust}

Quarry dust was obtained from the abundant deposits at Akamkpa quarry site in Akamkpa Local Government area of Cross River State; located at a few minutes' drive from Calabar Metropolis. The quarry dust had a specific gravity of 2.52 .

\section{Method}

This study employs two methods: analytical and experimental. The analytical method deals with the arrangement of points within the experimental region and selection of a second degree polynomial equation to represent the response surface over the entire region. The response in this case is the static modulus of elasticity of the laterite-quarry dust blocks. The response function is assumed to be multi-varied.

The response $y$ is expressed as a function of the actual proportions of the constituents of the mixture, $Z_{i}$ by [9]. The sum of all the proportions as in all mixture experiments must add up to 1 . That is:

$$
Z_{1}+Z_{2}+\cdots+Z_{q}=\sum_{I=1}^{q} Z_{i}=1
$$

He assumed that $y=F(Z)$, is continuous and differentiable with respect to its predictors, and can be expanded in the neighbourhood of a chosen point, $Z(0)$ using Taylor's series.

Thus,

$$
Z(0)=\left(Z_{1}^{(0)}, Z_{2}^{(0)}, \ldots, Z_{q}^{(0)}\right)^{T}
$$

$$
\begin{aligned}
y(Z)=F\left(Z^{(0)}\right)+ & \sum_{i=1}^{q} \frac{\partial f\left(Z^{(0)}\right)}{\partial Z_{i}}\left(Z_{i}-Z^{(0)}\right)+\frac{1}{2 !} \sum_{i=1}^{q-1} \sum_{j=1}^{q} \frac{\partial^{2} f\left(Z^{0}\right)}{\partial Z_{i} \partial Z_{j}}\left(Z_{i}-Z_{i}^{(0)}\right)\left(Z_{j}-Z_{j}^{(0)}\right) \\
& +\frac{1}{2 !} \sum_{i=1}^{q} \frac{\partial^{2} f\left(Z^{(0)}\right)}{\partial Z_{i}^{2}}\left(Z_{i}-Z^{(0)}\right) \ldots
\end{aligned}
$$

For convenience, the point $Z^{0}$ can be taken as the origin without loss in generality of the formulation.Thus

$$
Z_{1}^{(0)}=0, Z_{2}^{(0)}=0, \ldots, Z_{q}^{(0)}=0
$$

Let

$b_{0}=F(0), \quad b_{i}=\frac{\partial F(0)}{\partial Z_{i}}, \quad b_{i j}=\frac{\partial^{2} F(0)}{\partial Z_{i} \partial Z_{j}}, \quad b_{i i}=\frac{\partial^{2} F(0)}{\partial Z_{i}^{2}}$

Substituting Equation (2.41 5) into Equation (2.39 3) gives:

$y(Z)=b_{0}+\sum_{i=1}^{q} b_{i} Z_{i}+\sum_{i \leq j \leq q}^{q} b_{i j} Z_{i} Z_{j}+\sum_{i=1}^{q} b_{i i} Z_{i}^{2}$

The number of terms in Equation (6) is $C_{n}^{(q+n)}$

Multiplying Equation (1) by $b_{0}$ gives the expression:

$$
b_{0}=b_{0} Z_{1}+b_{0} Z_{2}+\cdots \ldots \ldots+b_{0} Z_{q}
$$

Multiplying Equation (1) successively by $Z_{1}, Z_{2} \ldots Z_{q}$ and rearranging, gives respectively:

$$
\begin{aligned}
& Z_{1}{ }^{2}=Z_{1}-Z_{1} Z_{2}-\ldots \ldots \ldots \ldots . Z_{1} Z_{q} \\
& Z_{2}{ }^{2}=Z_{2}-Z_{1} Z_{2}-\ldots \ldots \ldots-Z_{2} Z_{q} \\
& Z_{q}{ }^{2}=Z_{1}-Z_{1} Z_{q}-\ldots \ldots \ldots \ldots-Z_{(q-1)} Z_{q}
\end{aligned}
$$

Substituting Equations (7) and (8) into Equation (6) and simplifying yields Equation (2.459)

$y(Z)=\sum_{i=1}^{q} \beta_{i} Z_{i}+\sum_{i \leq j \leq q}^{q} \beta_{i j} Z_{i} Z_{j}$

Where

$$
\begin{gathered}
\beta_{i}=b_{0}+b_{i} \ldots \ldots+b_{i i} \\
\beta_{i j}=b_{i j}-b_{i i}-b_{i j}
\end{gathered}
$$

Equation (9) is Osadebe's regression model equation. It is defined if the unknown constant coefficients $\beta_{i}$ and $\beta_{i j}$ are uniquely determined.

If the number of constituents, $q$, is 4 , and the degree of the polynomial $n$, is 2 then Osadebe's regression equation is given as: 
$y=\beta_{1} Z_{1}+\beta_{2} Z_{2}+\beta_{3} Z_{3}+\beta_{4} Z_{4}+\beta_{12} Z_{1} Z_{2}+\beta_{13} Z_{1} Z_{3}+\beta_{14} Z_{1} Z_{4}$

$$
+\beta_{23} Z_{2} Z_{3}+\beta_{24} Z_{2} Z_{4}+\beta_{34} Z_{3} Z_{4}
$$

The number of coefficients, $N$ is the same as that for the Scheffe's $\{4,2\}$ model as provided by Equation 12 . That is:

$$
N=C_{n}^{(q+n-1)}=N=C_{2}^{(4+2-1)}=10
$$

The response function is generally expressed as:

$$
y(Z)=\sum_{i=1}^{q} \beta_{i} Z_{i}+\sum_{i \leq j \leq q}^{q} \beta_{i j} Z_{i} Z_{j}
$$

\section{Determination of the coefficients of the Osadebe's regression equation}

The least number of experimental runs or independent responses necessary to determine the coefficients of Osadebe's regression coefficients is $N$.

Let $\mathrm{y}^{(k)}$ be the response at point $k$ and the vector corresponding to the set of component proportions (predictors)

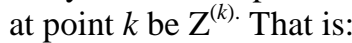

$\mathrm{Z}^{(k)}=\left\{\mathrm{Z}_{1}^{(k),} \mathrm{Z}_{2}^{(k)}, \ldots \ldots, \mathrm{Z}_{q}^{(k)}\right\}$

Substituting the vector of Equation (3) into Equation (12) gives:

$$
y^{(k)}=\sum_{i=1}^{q} \beta_{i} Z_{i}^{(k)}+\sum_{i \leq j \leq q}^{q} \beta_{i j} Z_{i}^{(k)} Z_{j}^{(k)} \quad k=1,2, \ldots, N
$$

Substituting the predictor vectors at each of the $N$ observation points successively into Equation (9) gives a set of $N$ linear algebraic equations which can be written in matrix form as:

$\boldsymbol{Z} \boldsymbol{\beta}=\boldsymbol{y}$

Where

$\boldsymbol{\beta}$ is a vector whose elements are the estimates of the regression coefficients.

$\boldsymbol{Z}$ is an $N x N$ matrix whose elements are the mixture component proportions

and functions of the component proportions.

$\boldsymbol{y}$ is a vector of the observations or responses at the various $N$ observation points.

The solution to Equation (16) is given as:

$$
\boldsymbol{\beta}=\boldsymbol{Z}^{-1} \boldsymbol{y}
$$

\section{Experimental method}

The pseudo proportion units were converted to actual mix proportion as indicated in table 1 . The actual mix proportions; water (Z1), cement (Z2), quarry dust (Z3), and laterite (Z4), were measured by weight and used to produce machine vibrated laterite- quarry dust hollow blocks of size $450 \mathrm{~mm} \times 150 \mathrm{~mm} \times 225 \mathrm{~mm}$. The blocks were cured for 28 days after 24 hours of demoulding by sprinkling with water in the morning and evening. They were tested for compressive strength using the universal compression testing machine, in accordance with BS EN 12390-4. The crushing load and net cross sectional area of the blocks were recorded. The compressive strength was obtained from the following relation:

$\mathrm{fc}=\mathrm{P} / \mathrm{A}$

Where $\mathrm{fc}=$ the compressive strength, $\mathrm{P}=$ crushing load, and $\mathrm{A}=$ cross-sectional area of the specimen

The Static modulus of elasticity for the block was computed as a function of compressive strength and density using the relation established by [10] represented as:

$E c=1.7 \rho^{2} f c^{0.33} * 10^{-6}$

Where,

$E c=$ Static modulus of Elasticity, $\rho=$ density and

$f_{c}=$ compressive strength

Table 1 below shows the design matrix in the pseudo and real ratios along with the experimental test results for the compressive strength and static modulus of elasticity.

Table 1: Experimental test results

\begin{tabular}{|l|l|l|l|l|l|l|l|l|l|l|}
\hline $\begin{array}{l}\text { S/ } \\
\text { N }\end{array}$ & \multicolumn{3}{|c|}{ Pseudo components units } & \multicolumn{3}{c|}{ Actual mix ratio } & \multicolumn{2}{l|}{ Average response (y) } \\
\cline { 2 - 12 } & $\begin{array}{l}\text { Water } \\
(\mathrm{X} 1)\end{array}$ & $\begin{array}{l}\text { Cement } \\
(\mathrm{X} 2)\end{array}$ & $\begin{array}{l}\text { Quarry dust } \\
(\mathrm{X} 3)\end{array}$ & $\begin{array}{l}\text { Laterite } \\
(\mathrm{X} 4)\end{array}$ & $\begin{array}{l}\text { Water } \\
(\mathrm{X} 1)\end{array}$ & $\begin{array}{l}\text { Cement } \\
(\mathrm{X} 2)\end{array}$ & $\begin{array}{l}\text { Quarry } \\
\text { dust } \\
(\mathrm{X} 3)\end{array}$ & $\begin{array}{l}\text { Laterite } \\
(\mathrm{X} 4)\end{array}$ & $\begin{array}{l}\text { Compressive } \\
\text { strength, } f_{c} \\
(\mathrm{Nmm})\end{array}$ & $\begin{array}{l}\text { Static modulus } \\
\text { of Elasticity } \\
(\mathrm{GPa})\end{array}$ \\
\hline 1 & 0 & 1 & 0 & 0 & 0.63 & 1 & 3.0 & 3.0 & 1.87 & 6.9476 \\
\hline 3 & 0.25 & 0.25 & 0.25 & 0.25 & 0.72 & 1 & 5.6 & 2.4 & 2.56 & 8.287 \\
\hline 3 & 1 & 0 & 0 & 0 & 0.54 & 1 & 5.4 & 0.6 & 2.50 & 8.8566 \\
\hline
\end{tabular}


Predicting Static Modulus of Elasticity of Laterite -Quarry Dust Blocks Using Osadebe's ..

\begin{tabular}{|l|l|l|l|l|l|l|l|l|l|l|}
\hline 4 & 0.5 & 0 & 0.5 & 0 & 0.67 & 1 & 7.2 & 0.8 & 2.24 & 7.9930 \\
\hline 5 & 0 & 0.5 & 0 & 0.5 & 0.77 & 1 & 4.0 & 4.0 & 2.37 & 8.2285 \\
\hline 6 & 0.5 & 0 & 0 & 0.5 & 0.72 & 1 & 5.2 & 2.8 & 2.37 & 8.0286 \\
\hline 7 & 0 & 0 & 1 & 0 & 0.80 & 1 & 9.0 & 1.0 & 1.81 & 7.9795 \\
\hline 8 & 0.125 & 0.125 & 0.125 & 0.625 & 0.81 & 1 & 5.3 & 3.7 & 2.42 & 8.6075 \\
\hline 9 & 0.5 & 0.5 & 0 & 0 & 0.58 & 1 & 4.2 & 1.8 & 2.56 & 8.3193 \\
\hline 10 & 0 & 0 & 0.5 & 0.5 & 0.85 & 1 & 7.0 & 3.0 & 2.09 & 8.1875 \\
\hline 11 & 0 & 1 & 0 & 0 & 0.63 & 1 & 3.0 & 3.0 & 1.89 & 7.0700 \\
\hline 12 & 0 & 0 & 0 & 1 & 0.90 & 1 & 5.0 & 5.0 & 2.20 & 7.6358 \\
\hline 13 & 1 & 0 & 0 & 0 & 0.54 & 1 & 5.4 & 0.6 & 2.45 & 8.4865 \\
\hline 14 & 0 & 0.5 & 0.5 & 0 & 0.72 & 1 & 6.0 & 2.0 & 2.54 & 8.8676 \\
\hline 15 & 0 & 0 & 0 & 1 & 0.90 & 1 & 5.0 & 5.0 & 2.20 & 8.56 \\
\hline 16 & 0.625 & 0.125 & 0.125 & 0.125 & 0.63 & 1 & 5.5 & 1.5 & 2.56 & 8.9084 \\
\hline 17 & 0 & 0 & 1 & 0 & 0.80 & 1 & 9.0 & 1.0 & 1.90 & 8.0343 \\
\hline 18 & 0.25 & 0.25 & 0.25 & 0.25 & 0.72 & 1 & 5.6 & 2.4 & 2.49 & 8.1386 \\
\hline 19 & 0.125 & 0.625 & 0.125 & 0.125 & 0.67 & 1 & 4.3 & 2.7 & 2.50 & 8.9417 \\
\hline 20 & 0.125 & 0.125 & 0.625 & 0.125 & 0.76 & 1 & 7.3 & 1.7 & 2.30 & 8.4656 \\
\hline
\end{tabular}

A total of 15 mixes were considered. Out of this number, 10 mixes were selected and used for the formulation of the model, while the remaining were used for validation of the model as shown in table 2.

The table also contained the average experimental values for compressive strength and static modulus of elasticity. Cells having two run order numbers indicate the replicate mixes and the response in this case is the average response for the replicate mixes.

Table 2: Actual and fractional mix for Osadebe

\begin{tabular}{|c|c|c|c|c|c|c|c|c|c|c|}
\hline \multirow{2}{*}{$\begin{array}{l}\text { Run } \\
\text { Order }\end{array}$} & \multicolumn{4}{|c|}{ Components in zctual ratios } & \multicolumn{4}{|c|}{ Component proportions } & \multicolumn{2}{|c|}{ Responses } \\
\hline & $\begin{array}{l}\text { Water } \\
\left(\mathrm{X}_{1}\right)\end{array}$ & $\begin{array}{c}\text { Cement } \\
\left(\mathrm{X}_{3}\right)\end{array}$ & $\begin{array}{l}\text { Quasny dust } \\
\left(\mathrm{X}_{3}\right)\end{array}$ & $\begin{array}{c}\text { Laterite } \\
\mathrm{X} \text {. }\end{array}$ & $\begin{array}{l}\text { Watee } \\
\left(Z_{1}\right)\end{array}$ & $\begin{array}{c}\text { Cement } \\
\left(\mathrm{Z}_{2}\right)\end{array}$ & $\begin{array}{c}\text { Quany dust } \\
\left(\mathbf{Z}_{j}\right)\end{array}$ & $\begin{array}{c}\text { Laterite } \\
\left(\mathrm{Z}_{4}\right)\end{array}$ & $\begin{array}{c}y_{t} \\
\text { Nmm }\end{array}$ & $\begin{array}{c}E c \\
\left(G P_{2}\right)\end{array}$ \\
\hline 3,13 & 0.54 & 1 & 5.4 & 0.6 & 0.071618 & 0.132626 & 0.716180 & 0.079576 & 2.48 & 8.6716 \\
\hline 9 & 0.585 & 1 & 4.2 & 1.8 & 0.077126 & 0.131839 & 0.553724 & 0.237310 & 256 & 8.3193 \\
\hline 4 & 0.67 & 1 & 72 & 0.8 & 0.069286 & 0.103413 & 0.744571 & 0.082730 & 2.24 & 79930 \\
\hline 6 & 0.72 & 1 & 5.2 & 2.8 & 0.074074 & 0.102881 & 0.534979 & 0.288066 & 2.37 & 8.0286 \\
\hline 1,11 & 0.63 & 1 & 3. & 3 & 0.082569 & 0.131062 & 0393185 & 0.393185 & 1.88 & 7.0088 \\
\hline 14 & 0.72 & 1 & 6 & 2 & 0.074074 & 0.102881 & 0.617284 & 0.205761 & 254 & 8.8676 \\
\hline 5 & 0.77 & 1 & 4 & 4 & 0.078813 & 0.102354 & 0.409417 & 0.409417 & 2,37 & 8.2285 \\
\hline 7,17 & 0.8 & 1 & 9 & 1 & 0.067797 & 0.084746 & 0.762712 & 0.084746 & 1.86 & 8.0069 \\
\hline 10 & 0.85 & 1 & 7 & 3 & 0.071730 & 0.084388 & 0,590717 & 0.253165 & 209 & 8.1875 \\
\hline 12,15 & 0.63 & 1 & 5.5 & 1.5 & 0.073001 & 0.115875 & 0.637312 & 0.173812 & 2.20 & 7.9252 \\
\hline \multicolumn{11}{|c|}{ MIXES FOR MODEL VALIDATION } \\
\hline 2.18 & 0.72 & 1 & 5.6 & 24 & 0.074074 & 0.102881 & 0.576132 & 0246914 & 253 & 8.2128 \\
\hline 16 & 0.63 & 1 & 5.5 & 1.5 & 0.073001 & 0.115875 & 0.637312 & 0.173812 & 256 & 8.9084 \\
\hline 19 & 0.674 & $i$ & 4.3 & 2.7 & 0.077703 & 0.115287 & 0.495734 & 0.311275 & 250 & 8.9417 \\
\hline 20 & 0.76 & 1 & 7.3 & 1.7 & 0.070632 & 0.092937 & 0,678439 & 0.157993 & 2.30 & 8.4656 \\
\hline 8 & 0.81 & 1 & 5,3 & 3.7 & 0.074931 & 0.092507 & 0.490287 & 0.342276 & 2.42 & 8.6075 \\
\hline
\end{tabular}

\section{Results And Discussion}

The test results of the compressive strength of the laterite-quarry dust blocks based on 28-day strength and corresponding static modulus of elasticity are presented as part of Table 1.

Formulation of Model equation for static modulus of elasticity

The elements of the $\mathrm{Z}$ matrix with reference to equation 17 are as provided in Table 3

Table 3: Elements of the $\mathbf{Z}$ matrix for the Osadebe's model

\begin{tabular}{|c|c|r|r|r|r|r|r|c|c|}
\hline $\mathrm{Z}_{1}$ & $\mathrm{Z}_{2}$ & $\mathrm{Z}_{3}$ & \multicolumn{1}{|c|}{$\mathrm{Z}_{4}$} & $\mathrm{Z}_{1} \mathrm{Z}_{2}$ & $\mathrm{Z}_{1} \mathrm{Z}_{3}$ & $\mathrm{Z}_{1} \mathrm{Z}_{4}$ & $\mathrm{Z}_{2} \mathrm{Z}_{3}$ & $\mathrm{Z}_{2} \mathrm{Z}_{4}$ & $\mathrm{Z}_{3} \mathrm{Z}_{4}$ \\
\hline 0.071618 & 0.132626 & 0.71618 & 0.079576 & 0.009498 & 0.051291 & 0.005699 & 0.094984 & 0.010554 & 0.05699 \\
\hline 0.077126 & 0.131839 & 0.553724 & 0.23731 & 0.010168 & 0.042707 & 0.018303 & 0.073003 & 0.031287 & 0.131405 \\
\hline 0.069286 & 0.103413 & 0.744571 & 0.08273 & 0.007165 & 0.051589 & 0.005732 & 0.076998 & 0.008555 & 0.061598 \\
\hline 0.074074 & 0.102881 & 0.534979 & 0.288066 & 0.007621 & 0.039628 & 0.021338 & 0.055039 & 0.029636 & 0.154109 \\
\hline 0.082569 & 0.131062 & 0.393185 & 0.393185 & 0.010822 & 0.032465 & 0.032465 & 0.051531 & 0.051531 & 0.154594 \\
\hline 0.074074 & 0.102881 & 0.617284 & 0.205761 & 0.007621 & 0.045725 & 0.015242 & 0.063507 & 0.021169 & 0.127013 \\
\hline 0.078813 & 0.102354 & 0.409417 & 0.409417 & 0.008067 & 0.032267 & 0.032267 & 0.041905 & 0.041905 & 0.167622 \\
\hline 0.067797 & 0.084746 & 0.762712 & 0.084746 & 0.005745 & 0.051709 & 0.005745 & 0.064637 & 0.007182 & 0.064637 \\
\hline 0.07173 & 0.084388 & 0.590717 & 0.253165 & 0.006053 & 0.042372 & 0.018159 & 0.04985 & 0.021364 & 0.149549 \\
\hline 0.07563 & 0.084034 & 0.420168 & 0.420168 & 0.006355 & 0.031777 & 0.031777 & 0.035308 & 0.035308 & 0.176541 \\
\hline
\end{tabular}


Substituting the numerical average replicate values of static modulus of elasticity observed at the ten design points of the simplex into Equation (17) and solving simultaneously gives the following values of the coefficients:

$$
\begin{array}{ll}
\beta_{1}=-72079.9872 & \beta_{2}=527.8603 \quad \beta_{3}=-406.1002 \beta_{4}=-736.4554 \\
\beta_{12}=80706.0764, & \beta_{13}=83672.7022 \quad \beta_{14}=87627.9165 \quad \beta_{23}=-1058.1584 \\
\beta_{24}=-982.6645 & \beta_{34}=58.9751
\end{array}
$$

The resulting second degree regression equation for Osadebe's model is given below:

$$
\begin{aligned}
\hat{\mathrm{y}}= & -72079.9872 Z_{1}+527.8603 Z_{2}-406.1002 Z_{3}-736.4554 Z_{4}+80706.0764 Z_{1} Z_{2} \\
& +83672.7022 Z_{1} Z_{3}+87627.9165 Z_{1} Z_{4}-1058.1584 Z_{2} Z_{3}-982.6645 Z_{2} Z_{4} \\
& +58.9751 Z_{3} Z_{4}
\end{aligned}
$$

\begin{tabular}{|c|c|c|c|c|c|c|}
\hline \multirow[t]{2}{*}{ Run Order } & \multicolumn{4}{|c|}{ Actual mix ratios } & \multirow{2}{*}{$\begin{array}{l}\text { Experimental } \\
\text { result } \\
(\mathrm{GPa})\end{array}$} & \multirow[b]{2}{*}{$\begin{array}{l}\text { Model predicted result } \\
\text { (Osadebe) GPa }\end{array}$} \\
\hline & Water & Cement & Quarry dust & Laterite & & \\
\hline 1 & 0.63 & 1 & 3 & 3 & 6.9476 & 6.95 \\
\hline 2 & 0.72 & 1 & 5.6 & 2.4 & 8.2870 & 8.55 \\
\hline 3 & 0.54 & 1 & 5.4 & 0.6 & 8.8566 & 8.49 \\
\hline 4 & 0.67 & 1 & 7.2 & 0.8 & 7.9930 & 7.99 \\
\hline 5 & 0.77 & 1 & 4 & 4 & 8.2285 & 8.23 \\
\hline 6 & 0.72 & 1 & 5.2 & 2.8 & 8.0286 & 8.03 \\
\hline 7 & 0.8 & 1 & 9 & 1 & 7.9795 & 7.98 \\
\hline 8 & 0.81 & 1 & 5.3 & 3.7 & 8.6075 & 8.18 \\
\hline 9 & 0.585 & 1 & 4.2 & 1.8 & 8.3193 & 8.32 \\
\hline 10 & 0.85 & 1 & 7 & 3 & 8.1875 & 8.19 \\
\hline 11 & 0.63 & 1 & 3 & 3 & 7.0700 & 6.95 \\
\hline 12 & 0.9 & 1 & 5 & 5 & 7.6358 & 7.64 \\
\hline 13 & 0.54 & 1 & 5.4 & 0.6 & 8.4865 & 8.49 \\
\hline 14 & 0.72 & 1 & 6 & 2 & 8.8676 & 8.87 \\
\hline 15 & 0.9 & 1 & 5 & 5 & 8.2145 & 7.64 \\
\hline 16 & 0.63 & 1 & 5.5 & 1.5 & 8.9084 & 8.41 \\
\hline 17 & 0.8 & 1 & 9 & 1 & 8.0343 & 7.98 \\
\hline 18 & 0.72 & 1 & 5.6 & 2.4 & 8.1386 & 8.55 \\
\hline 19 & 0.674 & 1 & 4.3 & 2.7 & 8.9417 & 8.34 \\
\hline 20 & 0.76 & 1 & 7.3 & 1.7 & 8.4656 & 8.41 \\
\hline
\end{tabular}

Table 4 presents the experimental and predicted values of static modulus of elasticity of the laterite quarry dust blocks.

Table 4: Experimental and model predicted Static modulus of elasticity results

\section{Test for adequacy of the model}

The model was tested for adequacy against the controlled experimental results. The hypotheses for the model are as follows:

Null Hypothesis $\left(\mathbf{H}_{\mathbf{0}}\right)$ : there is no significant difference between the experimental and the theoretical estimated results at a $95 \%$ confidence level

Alternative Hypothesis $\left(\mathrm{H}_{1}\right)$ : There is a significant difference between the experimental and theoretically expected result at a 95\% confidence level. The Fisher Test was used to test for the adequacy of the model. The analysis of variance for the Fisher test using [11] at the check point is as shown in Table 45 below. The calculated $\mathrm{F}$ from the table is 3.72 which is less than the critical (tabulated) F value of 5.05, justifying the adequacy of the model equation. Again the $p$-value of 0.088 which is greater than 0.05 further indicates the adequacy of the model.

Table 5: Analysis of Variance table for Static modulus of Elasticity (Osadebe's model)

\begin{tabular}{|l|l|l|l|l|l|}
\hline Run order & $y($ observed $)$ & $y($ predicted $)$ & & $y($ observed $)(G P a)$ & $Y($ predicted $)$ \\
\hline & $(G P a)$ & $(G P a)$ & & & $($ GPa $)$ \\
\hline 2 & 8.287 & 8.548 & Mean & 8.625167 & 8.359667 \\
\hline 18 & 8.139 & 8.548 & Variance & 0.118078 & 0.031698 \\
\hline 16 & 8.908 & 8.13 & Observations & 6 & 6 \\
\hline 19 & 8.942 & 8.341 & df & 5 & 5 \\
\hline
\end{tabular}


Predicting Static Modulus of Elasticity of Laterite -Quarry Dust Blocks Using Osadebe's ..

\begin{tabular}{|l|l|l|l|l|l|}
\hline 20 & 8.868 & 8.41 & $\mathrm{~F}$ & 3.725114 & \\
\hline 8 & 8.607 & 8.181 & $\mathrm{P}(\mathrm{F}<=\mathrm{f})$ one-tail & 0.087631 & \\
\hline & & & F Critical one-tail & 5.050329 & \\
\hline
\end{tabular}

\section{Normal probability plot}

Figure 1shows normal probability plot. The points in figure lie very close to the reference line with a $p$-value of 0.145 which is greater than 0.05 . The data therefore follow a normal distribution, thereby justifying the assumption required for use of analysis of variance

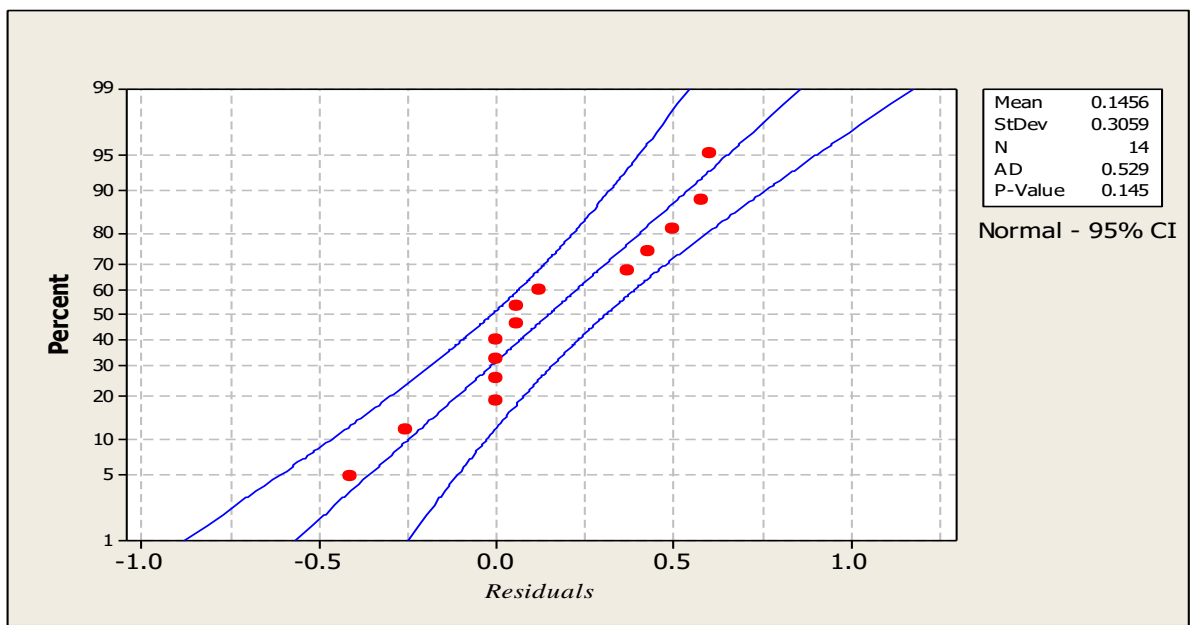

Figure 1: Normal probability plot for Static modulus of elasticity residuals Osadebe's model)

\section{Conclusion}

A mathematical model for predicting the static modulus of elasticity of laterite-quarry dust block based on actual proportions using Osadebe's theory was formulated. The model was tested for lack of fit and was found to be adequate. There was no significant difference between the experimented and predicted values.

\section{Reference}

[1]. Montgomery, D. E. (2002). Dynamically- Compacted cement stabilized soil blocks for low- cost Housing. A Phd Thesis in Engineering, University of Warwick.

[2]. Ilangovana, R., Mahendrana, N., and Nagamanib, K. (2008) Strength and durability properties of concrete containing quarry rock dust as fine aggregate. ARPN Journal of Engineering and Applied Science. Vol. 3 No. 5 pp 20-26

[3]. Oyekan, G. L. and Kamiyo, O. M (2008) Effects of Granite fines on some engineering properties of sandcrete blocks. A paper presented at $33^{\text {rd }}$ conference on our world in concrete and structure at Singapore.

[4]. Josphua, O., Amusan, L. M., Fagbenle, O. I. and Kukoyi, P. O. (2014): "Effects of Partial Replacement of sand with Lateritic soil in sandcrete blocks". Covenant Journal of research in Built Environment vol.1 No 2. pp 91-102

[5]. Okere, C. E., Onwuka, D. O., and Osadebe, N .N.( 2014): Static Modulus of Elasticity of sand- Laterite Blocks. International Journal of Engineering Science and Research Technology, pp 373-380

[6]. Anya, C. U. and Osadebe, N.N.(2015): Mixture Experiment model for predicting the compressive strength and water absorption of sand- quarry dust blocks. The international Journalof Engineering and Science, pp 27-31

[7]. Onuamah, P. N. and Osadebe, N. N. ( 2015) Development of Optimized strength model of lateritic hollow block with 4\% mould soil inclusion. Nigerian Journal of Technology, Nsukka, Nigeria. 34(1) pp 1-11

[8]. Osuji, S. O. and Egbon, B. N.(2015) "Optimizing compressive strength characteristics of hollow building blocks from granite quarry dust and sand. Nigerian Journal of Techniogy Vol 34 No 3, pp 478- 483

[9]. Osadebe, N. N. (2003). "Generalized mathematical modelling of compressive strength of normal concrete as a multi-variant function of the properties of its constituent components", A paper delivered at the College of Engineering, University of Nigeria, Nsukka. 2003

[10]. Neville, A. M. and Brooks, J. J. (1987). Concrete Technology, Pearson Education Ltd Partpargani, Delhi 110 092, India.

[11]. Microsoft Inc. (2010): Microsoft Excel (2010) Microsoft Inc. Redmond Campus Washington U.S. A. 